Bangladesh J. Plant Taxon. 16(1): 37-46, 2009 (June)

(C) 2009 Bangladesh Association of Plant Taxonomists

\title{
POLLEN MORPHOLOGY AND SYSTEMATICS IN TWO SUBFAMILIES OF ERICACEAE: CASSIOPOIDEAE AND HARRIMANELLOIDEAE
}

\author{
A.K.M. Golam SARWAR ${ }^{1}$ AND HidEKI TAKAHASHI ${ }^{2}$ \\ Laboratory of Systematic Botany, Graduate School of Agriculture, \\ Hokkaido University, Japan.
}

Keywords: Pollen morphology; Systematics; Cassiopoideae; Harrimanelloideae; Ericaceae.

\begin{abstract}
Pollen morphology of two subfamilies of Ericaceae, Cassiopoideae and Harrimanelloideae, was studied using light microscopy (LM), scanning electron microscopy (SEM), and also, for selected species, transmission electron microscopy (TEM). The systematic significance of new palynological data is discussed in the light of the recent classification of Ericaceae. The Cassiopoideae are stenopalynous; the four 3aperturate grains are united in compact minute tetrads with striate apoclopial exine sculpture. Infra- and inter-specific variations have been observed in some palynological features of Cassiope, this might be due to geographical distribution. The Harrimanelloideae pollen grain is characterized by minute tetrahedral tetrads with coarsely rugulate to psilate apoclopial exine sculpture and perforated septum. Pollen morphology supports the subfamilial status of Cassiopoideae and Harrimanelloideae, and the close relationship between the members of subfamily Harrimanelloideae and Vaccinioideae. The secondary sculpture on the exine surface might be a synapomorphic palynological character state for Harrimanelloideae + Styphelioideae + Vaccinioideae clade.
\end{abstract}

\section{Introduction}

The cosmopolitan family Ericaceae comprises eight subfamilies, approximately 125 genera and 4100 species. Although members of this family are highly diverse in life forms, leaf morphology, and inflorescence characteristics, three of these subfamilies viz., Enkianthoideae, Cassiopoideae and Harrimanelloideae, are monogeneric (Kron et al., 2002; Kron and Luteyn, 2005). The systematic position of subfamilies; Cassiopoideae and Harrimanelloideae, have been discussed variously. Cox (1948) first proposed a new tribe, Cassiopeae, in the subfamily Vaccinioideae, which included the genera Cassiope, Harrimanella, Epigaea, Enkianthus and Agauria on the basis of similar wood anatomy. Later, Stevens (1971) reassessed the generic limits of the tribe Cassiopeae with only Cassiope and Harrimanella, although he reported much dissimilarity between these two genera. The cladistic studies showed that Cassiope and Harrimanella (as member of the tribe Cassiopeae sensu Stevens, 1971) form a sister clade to Ericoideae (including Ericeae-Empetreae-Rhodoreae clade). Hence they are cladistically closer to Ericeae (Ericeae and Calluneae sensu Watson et al., 1967) than to any part of the Vaccinioideae (Anderberg, 1993). The latest classification of Ericaceae identified them as the member

\footnotetext{
${ }^{1}$ Corresponding author. Present address: Department of Crop Botany, Bangladesh Agricultural University, Mymensingh 2202, Bangladesh. E-mail: gsshameem@gmail.com

2 The Hokkaido University Museum, North 10 West 8, Sapporo 060-0810, Japan.
} 
of two monogeneric subfamilies; Cassiopoideae, the sister group of subfamily Ericoideae, and Harrimanelloideae, the sister group of Styphelioideae + Vaccinioideae clade (Kron et al., 2002).

The subfamily Cassiopoideae comprises only genus Cassiope with about 12 species of circumboreal distribution, extending south into China, the Himalayan region, Japan, Russia, and Pacific North America (Kron and Luteyn, 2005). This genus possesses some apomorphic character states, e.g. Calluna-type pith, decussate leaves, indumentum of fasciculate branched hairs and one-flowered axillary inflorescence with 4-6 basal bracteoles (Stevens, 1971; Kron et al., 2002), and the only member of the Ericaceae with bisporic embryo sac (Palser, 1952).

Harrimanella, the only genus of the other subfamily Harrimanelloideae, comprises two species, with a disjunct circumboreal distribution; from North America, Greenland, north Scandinavia to west Russia, Kamchatka, and north Japan (Kron and Luteyn, 2005). Subfamily Harrimanelloideae also possesses some apomorphic character states, e.g. indumentum of only unicellular hairs, inflorescence terminal, flowers solitary, bract and bracteoles lacking, and short and stout stigma (Kron et al., 2002).

Pollen morphology might play an important role in distinguishing among subfamilies of Ericaceae like Enkianthoideae (Kron et al., 2002; Sarwar and Takahashi, 2006a). Hitherto, all previous studies of pollen morphology of members of Cassiopoideae and Harrimanelloideae were done by only light microscopy (LM) (Yang, 1952; Sladkov, 1953, 1954; Ueno, 1962; Nair, 1965; Stevens, 1971; Moriya, 1976; Comtois and Larouche, 1981; Warner and Chinnappa, 1986; Ikuse, 2001). The data from pollen morphology has not been significantly used for taxonomic purposes. Therefore, the present research was undertaken to study the pollen morphology of Cassiope and Harrimanella in detail with the combination of LM, scanning electron microscopy (SEM) and transmission electron microscopy (TEM), and to discuss the systematic significance of new pollen morphological data in the light of the recent classification of Ericaceae (Kron et al., 2002).

\section{Materials and Methods}

Pollen morphology of four species, representing both genera of the monogeneric subfamilies Cassiopoideae and Harrimanelloideae was examined with LM and SEM (Table 1). Pollen grains of Cassiope lycopodiodes and Harrimanella stelleriana were studied especially with TEM. Polliniferous materials used in this study were taken from dried specimens available from the herbaria of Hokkaido University Museum (SAPS), University of Copenhagen (C) and University of Gothenburg (GB).

Preparation of pollen grains followed Sarwar et al. (2006a). Pollen samples were acetolysed following the standard procedure of Erdtman (1960) with little modification, and after the dehydration in an ethanol series, acetolysed pollen was embedded in silicone 
oil for LM observations. The following measurements were carried out with LM within one week after the preparation making. The main dimensions $D, P, d(E)$ and $2 f$ corresponding to the tetrad diameter, polar length and equatorial diameter of a single pollen grain within the tetrad, and total length of two concurrent apertures (colpi) were measured, and the ratios of D/d, P/E and 2f/D were calculated. Furthermore, width (W) of apertures, thickness of apocolpial exine and septum (inner wall) were measured. The measurements given in Table 3 are based on at least 10 grains from each specimen. Pollen slides and SEM stubs of all collections are deposited in the Hokkaido University Museum, Sapporo, and in part, in the Palynological Laboratory of Swedish Museum of Natural History, Stockholm. Descriptive terminology follows Punt et al. (1994) and Sarwar et al. (2006a).

Table 1. Specimens of the subfamilies of Cassiopoideae and Harrimanelloideae examined.

\begin{tabular}{l}
\hline Voucher information (Herbarium acronym) \\
\hline Subfamily Cassiopoideae \\
Cassiope fastigiata D. Don. Bhutan: Shringe, Me La, 08.06.1949. F. Loulow, G. Sherriff \& J. Hicks \\
20708 (GB) \\
C. lycopodiodes (Pall.) D. Don. Japan: Hokkaido, Kawakami-sicho, Kawakami-gun, Mts. Daisetsu, \\
Sugataminoike - Susoaidaira, 16.07.1987. H. Takahashi et al. 7185 (SAPS) \\
USA: Alaska, Mt. Marathon, Seward, Kenai Pen. $60^{0} 06^{\prime}$ N, $149^{0} 27^{\prime}$ W, 13.07.1951. J.A. Calder \\
$\quad 5850$ (C) \\
C. mertensiana (Bong.) G. Don. Canada: British Columbia, Mt. Revelstoke Nat. Park, vicinity of Heather \\
lodge, 22.07.1953. J.A. Calder \& D.B.O. Savile 10837 (C) \\
Subfamily Harrimanelloideae \\
Harrimanella stelleriana (Pall.) Cov. Japan: Hokkaido, Daisetsu, Mt. Ashi-dake, Sugatamino-ike, \\
20.06.1982. H. Takahashi 2513 (SAPS)
\end{tabular}

\section{Results}

\section{Subfamily Cassiopoideae}

In LM, the pollen grains are united in compact tetrahedral tetrad (Figs 1A-C). The average values of species ranged as follows: D 24.4-30.3 $\mu \mathrm{m}, \mathrm{P} 12.8-15.4 \mu \mathrm{m}, \mathrm{d}$ 17.0$22.5 \mu \mathrm{m}, \mathrm{D} / \mathrm{d}$ 1.34-1.49 (Table 3); oblate or suboblate; three aperturate (colpus), colpor(oid)ate, colpi distinct, but faint in C. fastigiata, 2f 17.2-22.4 $\mu \mathrm{m}$, W 0.6-1.0 $\mu \mathrm{m}$, wider at middle, acute towards end, tip often bifurcated in one specimen of $C$. lycopodiodes (Calder 5850), costae present, indistinct in C. fastigiata; endocracks absent or indistinct, present in C. lycopodiodes (Takahashi et al. 7185); endoaperture distinct, lalongate; exine tectate, apocolpial exine 0.9-1.7 $\mu \mathrm{m}$ thick, septum 0.7-1.1 $\mu \mathrm{m}$ thick, apocolpial exine sculpture varied from finely verrucate to finely rugulate or psilate (Tables 2 \& 3).

In SEM, the pollen surface is somewhat flat and the apocolpial exine sculpture is striate (Type S; Figs 1D-F). Colpi are narrow and elongate and the apocolpial region is 
small; aperture membranes are smooth in C. fastigiata and C. lycopodiodes, but granulate in C. mertensiana (Table 2).

TEM showed that in C. lycopodiodes (Takahashi et al. 7185), the apocolpial exine is composed of ektexine; tectum, columellae (rod-like elements distinct) and a foot layer, and endexine with higher electron density (Figs 1G-I). Sexine is ca $0.4 \mu \mathrm{m}$ thick, endexine thick and (endo)cracks present, and a total exine is ca $0.8 \mu \mathrm{m}$ thick (Fig. 1H). In the septum (proximal exine), tectum is lacking or fragmentary, two foot layers of adjacent grains are connected by columellae, the septum is ca 0.5-0.8 $\mu \mathrm{m}$ thick (Fig. 1I). Intine is almost evenly thick around the pollen tetrad, showing a lower electron density than the endexine at both apocolpial and septal exine.
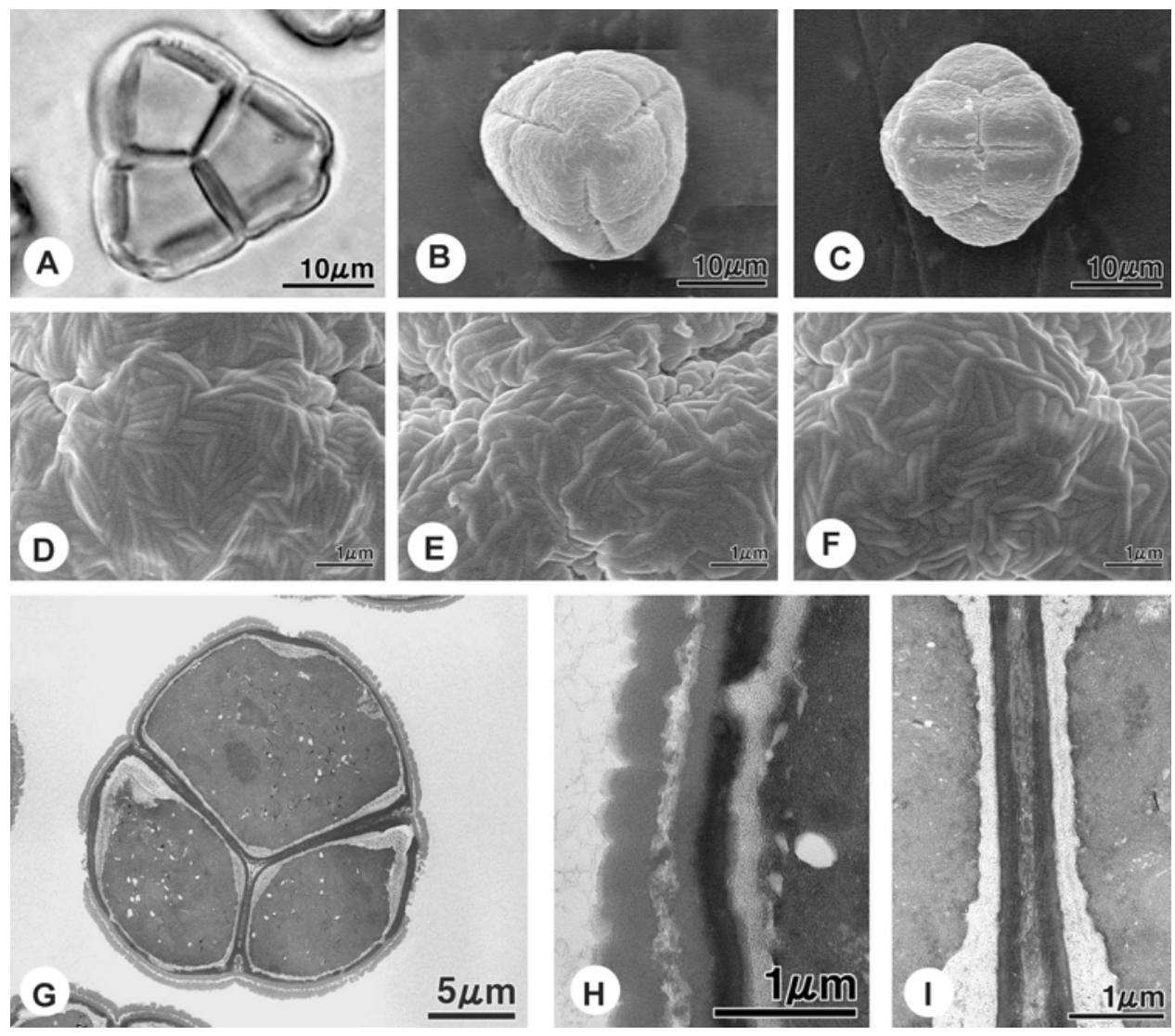

Fig. 1. LM, SEM and TEM micrographs of Cassiope pollen grains. A, D. C. fastigiata (Ludlow et al. 20708); B, F. C. mertensiana (Calder \& Savile 10837); C, E. G-I. C. lycopodiodes (Takahashi et al. 7185). A, B. Pollen tetrads at polar view; C. pollen tetrads at equatorial view; D-F, micrographs with apocolpial exine sculpture details; G. whole tetrads showing thick intine layer near aperture region; H. apocolpial exine showing tectum with striae, columellae, foot layer and thick endexine with (endo)cracks; I. in septum, tectum fragmentary, two foot layers of adjacent grains sometimes connected by columellae, endexine and thick intine. 


\section{Subfamily Harrimanelloideae}

In LM, pollen grains of Harrimanella stelleriana are commonly united in tetrahedral tetrads (Figs 2A-C) and the grains often shrink. In this species, the pollen grains are oblate; three aperturate, colporate, colpi slit-like, costae present; endocracks present; endoaperture distinct, lalongate; exine tectate, apocolpial region small, exine sculpture varies from psilate or finely rugulate. Qualitative and quantitative data on different pollen grain features of this species are given in Tables $2 \& 3$.

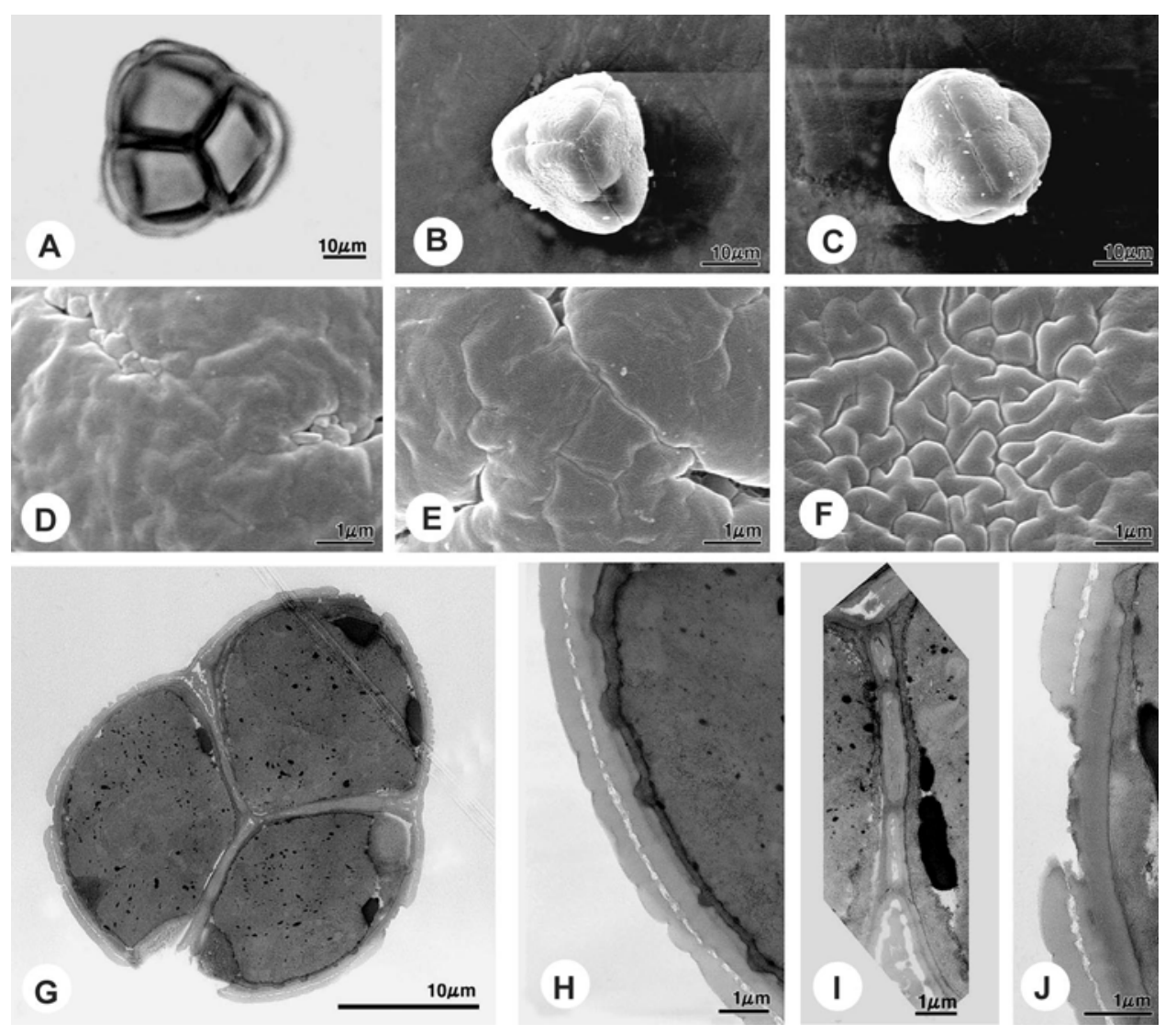

Fig. 2. LM, SEM and TEM micrographs of Harrimanella stelleriana pollen grains (Takahashi 2513). A, B. Pollen tetrads at polar view; C. pollen tetrads at equatorial view; D, E. micrographs with apocolpial exine sculpture details; F. micrographs with mescolpial exine sculpture details; G. whole tetrads; $\mathrm{H}$. apocolpial exine showing tectum, columellae, thick foot layer with (endo)cracks and endexine indistinguishable; I. septum faintly perforated, tectum fragmentary, two foot layers of adjacent grains sometimes connected by columellae, very thin or indistinguishable endexine and thick intine; J. aperture region characterized by thick foot layer, thin endexine and thick intine.

In SEM, the pollen surface is somewhat flat with an apocolpial exine sculpture that is coarsely rugulate to psilate, but intermediate types (R/P in Fig. 2D; R/RS in Fig. 2E). Exine sculpture along the colpi is similar to that appearing at the distal pole (apocol- 
pium), but the mesocolpial exine has a tendency to decrease the lateral extension of the rugulae into more distinct units (Fig. 2F). Aperture membrane is granulate (Table 2).

Table 2. Qualitative pollen morphological data of the subfamilies Cassiopoideae and Harrimanelloideae. CT, compact tetrad; T, tetrahedral tetrad; S, striate; R, rugulate; P, psilate; RS, rugulate-striate.

\begin{tabular}{|c|c|c|c|c|}
\hline Names of taxa & $\begin{array}{l}\text { Config- } \\
\text { uration }\end{array}$ & $\begin{array}{l}\text { Orname- } \\
\text { ntation }\end{array}$ & $\begin{array}{l}\text { Aperture } \\
\text { membrane }\end{array}$ & Remarks \\
\hline \multicolumn{5}{|l|}{ Subfamily Cassiopoideae } \\
\hline Cassiope fastigiata & CT & $\mathrm{S}$ & Smooth & Colpi faint \\
\hline C. lycopodiodes Takahashi et al. 7185 & CT & $\mathrm{S}$ & Smooth & Endocracks distinct \\
\hline Calder 5850 & CT & S & Smooth & $\begin{array}{l}\text { Ora indistinct, colpi often } \\
\text { bifurcated }\end{array}$ \\
\hline C. mertensiana & CT & $\mathrm{S}$ & Granulate & \\
\hline $\begin{array}{l}\text { Subfamily Harrimanelloideae } \\
\text { Harrimanella stelleriana }\end{array}$ & $\mathrm{T}$ & $\mathrm{R} / \mathrm{P}$ or $\mathrm{R} / \mathrm{RS}$ & Granulate & Grains often shrink \\
\hline
\end{tabular}

In TEM, the apocolpial exine is composed of ektexine and endexine (Figs 2G-I). The sexine is ca $0.5 \mu \mathrm{m}$ thick, endexine thick and (endo)cracks present, and a total exine is ca $1.1 \mu \mathrm{m}$ thick (Fig. 2H). In the septum (proximal exine), the tectum is lacking or fragmentary, two foot layers of adjacent grains are connected by columellae; the septum is ca 0.6-1.1 $\mu \mathrm{m}$ thick, faintly perforated, and thicker towards peripheral regions (Fig. 2I). Intine is almost evenly thick around the pollen tetrad, showing lower electron density than the endexine at both apocolpial and septal exine. The aperture region is characterized by a thick foot layer, thin endexine and thick intine (Fig. 2J).

\section{Discussion}

All taxa of Cassiope examined in this study have minute and 3-colpor(oid)ate grains united in compact tetrahedral tetrads having the similar exine sculpture of Type S. This suggests that the genus Cassiope, as a whole, is a well-defined entity. Members of Cassiope showed some distinct palynological characteristics e.g. consistently minute pollen grains. The apocolpial exine sculpture (Type $S$ ) is rarely found among the members of Ericaceae (Sarwar, 2007), which strongly supports its monophyly and present placement in the monogeneric subfamily Cassiopoideae. Another characteristic palynological feature of Cassiope, the ratio of aperture length to tetrad diameter (2f/D) is relatively larger compared to other Ericaceous taxa (Sarwar, 2007). The larger 2f/D resulted into pollen grains with the smaller/narrower apocolpial region in these taxa.

Although the Cassiope species studied showed the characteristic similarity in some palynological features, some infra- and inter-specific variations have also been observed. The Old World taxa possessed relatively smaller pollen tetrads and narrower aperture, but 
POLLEN MORPHOLOGY AND SYSTEMATICS IN ERICACEAE

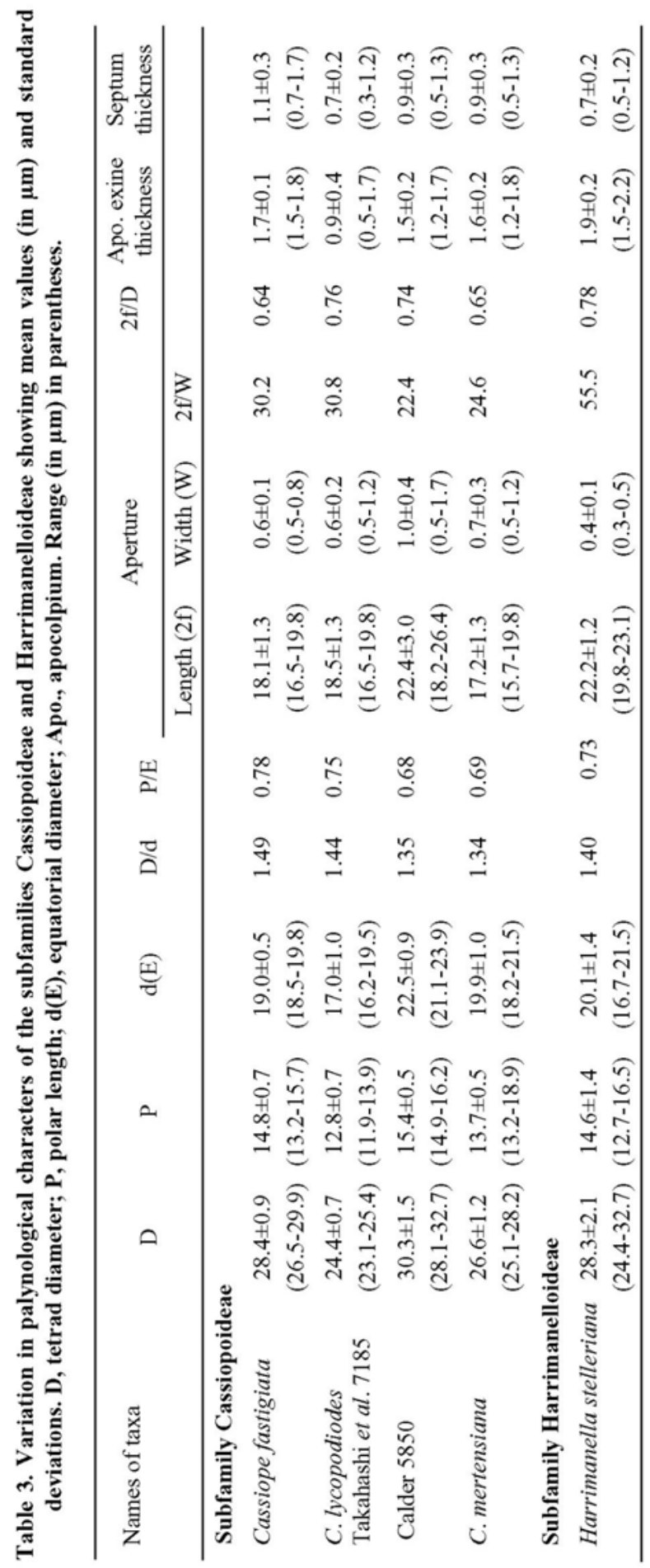


relatively larger D/d, P/E and 2f/W compared to those of New World taxa. It was very interesting that the two specimens of $C$. lycopodiodes showed variation in all quantitative palynological characters except 2f/D and septum thickness. These differences may be due to their geographic distribution. Infrageneric geographical variation in palynological characters also have been found in other taxa (Sarwar and Tahahashi, 2006a, c). Therefore, further study, with larger number of specimens, is necessary to clarify and/or confirm whether these differences are due to their geographic position or just random variation.

The pollen grain of Harrimanella is commonly minute in size. Our measurements agree with the results of previous studies (Ikuse, 2001). Pollen tetrads of H. stelleriana were often shrunken and/or broken and probably susceptible to acetolysis. Many other factors, viz. the poorly developed exine caused by genetic abnormalities and/or obstruction during pollen development process, thin tectum, poorly developed septum wall, and heterodynamosporus tetrads, either independently or collectively might be responsible for the shrinkage of pollen grains in Ericaceae (Sarwar, 2007). The ratio of aperture length to width (2f/W) in Harrimanella is relatively larger compared to other Ericaceous taxa (Sarwar, 2007), which may also indicate to the higher adaptibility of $H$. stelleriana to drier high Alpine regions of Japan (H. Takahashi, personal observations). By reducing the water losses through the narrow slit-like colpi, plants might be able to retain/increase viability of their pollen and improve the reproductive success in drier habitats.

Although most of the quantitative palynological characters are very similar in both the genera Cassiope and Harrimanella, tetrad shape, 2f/W and the apocolpial exine sculpture differed significantly between these two genera. Moreover, the septum of Harrimanella is perforated. Although the septum with perforations is not a rare palynological feature in the families having pollen tetrads, this character is characterized only a few other taxa of Ericaceae, e.g. Andromeda and Arctostaphylos, and has emerged as a character of taxonomic importance within this family (Sarwar, 2007). The distinct difference in exine sculpture and septum structure between these two genera might support and confirm their placement in two different monotypic subfamilies Cassiopoideae and Harrimanelloideae (Kron et al., 2002), as the apocolpial exine sculpture emerged as palynological character of the most important taxonomic utility within the family Ericaceae (Sarwar, 2007; Sarwar et al., 2008).

The rugulae with secondary sculpture, faintly striate in Harrimanella may also support their close relationship with the members of subfamily Vaccinioideae (Sarwar and Takahashi, 2006b, c, 2007; Sarwar et al., 2006a, b). Pollen grains united in tetrahedral tetrads and the secondary sculpture might be synapomorphic palynological character states for Harrimanelloideae + Styphelioideae + Vaccinioideae clade (Sarwar, 2007; Sarwar and Takahashi, 2006b, c, 2007; Sarwar et al., 2006a, b). 


\section{Acknowledgements}

The authors wish to express their sincere thanks to the Directors and Curators of SAPS, C and GB for allowing them to examine and/or for sending specimens on loan to sample polliniferous materials. Particular thanks are due to Mr. Toshiaki Ito of Electron Microscopy Laboratory, Graduate School of Agriculture, Hokkaido University for his technical assistance during the electron microscopic studies and photography of pollen grains. The first author is thankful to Ministry of Education, Culture, Sports, Science and Technology (MEXT) of Japan for Monbukagakusho Scholarship during the period of this study.

\section{References}

Anderberg, A.A. 1993. Cladistic interrelationships and major clades of the Ericales. Plant Syst. Evol. 184: 207-231.

Comtois, P. and Larouche, A. 1981. Morphologie pollinique des Éricales du Québec. Natur. Can. 108: 245262. (in French)

Cox, H.T. 1948. Studies in the comparative anatomy of the Ericales 2. Ericaceae subfamily Arbutoideae. Am. Midl. Nat. 40: 493-516.

Erdtman, G. 1960. The acetolysis method - A revised description. Svensk Bot. Tidskr. 54: 561-564.

Ikuse, M. 2001. Pollen grains of Japan. 2nd ed. Hirokawa Pub. Co., Tokyo, pp. 1-259 + pls 1-369. (in Japanese)

Kron, K.A. and Luteyn, J.L. 2005. Origin and biogeographic patterns in Ericaceae: New insight from recent phylogenetic analyses. In: Friis, Ib. and Balslev, H. (eds), Plant Diversity and Complexity Pattern Local, Regional and Global Dimensions. Biol. Skrifter 55. The Roy. Aca. Sci. Lett., Copenhagen, pp. 479-500.

Kron, K.A., Judd, W.S., Stevens, P.F., Crayn, D.M., Anderberg, A.A., Gadek, P.A., Quinn, C.J. and Luteyn, J.L. 2002. Phylogenetic classification of Ericaceae: molecular and morphological evidence. Bot. Rev. 68: 335-423.

Moriya, K. 1976. Flora and Palynomorphs of Alaska. Kodansha, Tokyo, pp. 288-297 + pls 124-136. (in Japanese)

Nair, P.K.K. 1965. Pollen Grains of Western Himalayan Plants. Asia Publ. House, Bombay, pp. 1-102.

Palser, B.F. 1952. Studies in the floral morphology of the Ericales 2. Megasporogenesis and megagametophyte development in the Andromedeae. Bot. Gaz. 114: 33-52.

Punt, W., Blackmore, S., Nilsson, S. and Le Thomas, A. 1994. Glossary of pollen and spore terminology. LPP Contrib. Ser. 1, LPP Found., Utrecht, pp. 1-71.

Sarwar, A.K.M. Golam 2007. Pollen morphology and its systematic significance in the Ericaceae. Ph.D. dissertation, Graduate school of Agriculture, Hokkaido University, Japan, pp. 1-302. (unpublished)

Sarwar, A.K.M. Golam and Takahashi, H. 2006a. Pollen morphology of Enkianthus (Ericaceae) and its taxonomic significance. Grana 45: 161-174.

Sarwar, A.K.M. Golam and Takahashi, H. 2006b. The taxonomic significance of pollen morphology in Andromedeae s.s., Gaultherieae, Lyonieae and Oxydendreae (Ericaceae: Vaccinioideae). Jpn. J. Palynol. 52: 77-96. 
Sarwar, A.K.M. Golam and Takahashi, H. 2006c. Pollen morphology of Pieris D. Don (Lyonieae, Ericaceae) and its taxonomic significance. J. Jpn. Bot. 81: 225-234.

Sarwar, A.K.M. Golam and Takahashi, H. 2007. An overview of pollen morphology and its systematic significance within the blueberry tribe Vaccinieae (Vaccinioideae; Ericaceae). Jpn. J. Palynol. 53: 87-104.

Sarwar, A.K.M. Golam, Ito, T. and Takahashi, H. 2006a. Pollen of Ceratostema Jussieu (Ericaceae, Vaccinieae): Tetrads without septa. J. Plant Res. 119: 685-689.

Sarwar, A.K.M. Golam, Ito, T. and Takahashi, H. 2006b. An overview of pollen morphology and its relevance to the sectional classification of Vaccinium L. (Ericaceae). Jpn. J. Palynol. 52: 15-34.

Sarwar, A.K.M. Golam, Ito, T. and Takahashi, H. 2008. An overview of pollen morphology in subfamily Arbutoideae (Ericaceae), and its systematic significance. Jpn. J. Palynol. 54: 79-92.

Sladkov, A.N. 1953. About morphological traits of pollen of Ericaceae. Proc. USSR Acad. Sci. 92: 10651068. (in Russian)

Sladkov, A.N. 1954. Morphological description of the pollen of the Pyrolaceae, Monotropaceae, Ericaceae, Vacciniaceae and Empetraceae of the European part of USSR. Works Inst. Geo. USSR Acad. Sci. 61: 119-156. (in Russian)

Stevens, P.F. 1971. A classification of the Ericaceae: subfamilies and tribes. Bot. J. Linn. Soc. 64: 1-53.

Ueno, J. 1962. Palynological notes on Ericaceae and Pyrolaceae from Japan and its neighbours. Acta Phytotaxo. Geobot. 20: 101-111. (in Japanese with English abstract)

Warner, B.G. and Chinnappa, C.C. 1986. Taxonomic implications and evolutionary trends in Canadian Ericales. Can. J. Bot. 64: 3113-3126.

Watson, L., William, W.T. and Lance, G.N. 1967. A mix-data approach to Angiosperm taxonomy: the classification of Ericales. Proc. Linn. Soc. London 178: 25-35.

Yang, B.Y. 1952. Pollen grain morphology in the Ericaceae. Quar. J. Taiwan Mus. 5: 1-24. (in Chinese)

(Manuscript received on 18 February 2009; revised on 29 March 2009) 